\title{
Esophageal Achalasia
}

National Cancer Institute

\section{Source}

National Cancer Institute. Esophageal Achalasia. NCI Thesaurus. Code C84699.

A finding indicating the lack of adequate relaxation of the lower esophageal sphincter resulting in difficulty swallowing food. 